Proceedings of the 2002 Winter Simulation Conference

E. Yücesan, C.-H. Chen, J. L. Snowdon, and J. M. Charnes, eds.

\title{
EVALUATION OF ARMY CORPS ARTILLERY AMMUNITION SUPPLY SYSTEMS VIA SIMULATION
}

\author{
Ihsan Sabuncuoglu \\ Department of Industrial Engineering \\ Bilkent University \\ 06533 Ankara, TURKEY
}

\author{
Durdu Hakan Utku \\ Academic Counseling and Education Center \\ Turkish Military Academy \\ 06654 Ankara, TURKEY
}

\begin{abstract}
The purpose of this paper is to discuss the evaluation of different alternatives for the implementation of Turkish army corps artillery ammunition supply system. The objective is to see whether the alternative systems operate properly and to select the best system design. We find that the first alternative system cannot supply the units for all phases of an eight-day battle time while the second, the third, and the fourth systems can supply and yield better results. The third system is less costly than the second and the fourth systems. However, it has the drawback of too many vehicles in the convoy (i.e. congestion) which makes it susceptible to the enemy long distance and air assaults. The fourth system is the best of all from the point of the performance it yields; but, it costs more compared to the other systems.
\end{abstract}

\section{INTRODUCTION}

The purpose of the ammunition supply is to provide the ammunition to the military units in time wherever it is needed to gain the maximum support to their operation plans. We develop four simulation models of the army corps artillery ammunition supply system. The first and the second models are the main models and the third and the fourth are the modified versions of the first two models. The scenario under consideration is the offense of the corps for an eightday battle time. The models include the activities of consuming the ammunition, reporting the consumed ammunition to the related commands, loading and unloading of ammunition in ASP, movement of convoys, and advancing of the units during the battle time. The objectives of this study are to examine the behavior of these four alternatives of army corps ammunition supply systems, establish the nature of the relationships among one or more significant factors and the systems' responses, see whether these systems operate properly, and select the best system design.

In the literature, there are a few studies. Parker [4] developed a simulation model to analyze the deployment strategies of combat, combat support, and service support units. Parsons and Krause [5] proposed a simulation model to study the delivery of logistics material to U.S. Marine Expeditionary Forces. Carr and Way [3] developed a rail simulation to represent the entire rail operation since the complexity of the process and system interaction required a dynamic simulation model. The model describes the loading, staging, travel, and unloading of rail cars at a facility and two distribution centers. In another study, Angelides [1] develops a simulation model for the material supply for an offshore pipeline construction by using an objectoriented environment. The model is applied to the loading of the barge at the coating yard, the transportation of the material to the pipe-laying site, and the pipe-laying activity performed by the pipeline vessel.

The rest of the paper is organized as follows. In Section 2, we give a brief information about the systems modeled in our study. In Section 3, we present the simulation models and discuss the validation issues. The results are presented in Section 4. Concluding remarks and the future research discussions are given in Section 5.

\section{SYSTEMS CONSIDERED}

The first system employs supply point distribution method (SPDM) for the units that are subunits of corps and distribution to the unit distribution method (DUDM) for the units that are the sub units of army. In SPDM, the units send their supply vehicles to the supply point, take the ammunition, and come back to their battle area. In DUDM, ammunition is directly obtained by the vehicles of the army to the ammunition supply points.

In the second system, only the DUDM is used for all phases of the supply. All of the logistic activities of the army are commanded by the Army Logistics Management Center (ALMC). The transportation issues are planned by the Transportation Center, which is a subdepartment of ALMC. ALMC is informed by use of an on-line network about the consumed ammunition by the brigades. As the information is gained by the ALMC, it is decided which ASP is responsible for the supply of the related brigade and 
which transportation unit is responsible for the transportation of this ammunition. The third alternative system is a modified version of the first system. This supply system differs from the first system by having an on-line report system, having a modern material handling system for loading the ammunition and more convoy vehicle loading capacity while the first system has classical report system, manpower for loading and unloading, and few convoy vehicle loading capacity, correspondingly.

The fourth alternative system is a modified version of the second system. This system is similar to the second system except for having more convoys and vehicles loading capacity instead of having few convoy and vehicle loading capacity as in the second alternative system. The main difference between the two systems is the convoy and the vehicle loading capacities.

\section{SIMULATION MODELLING}

The simulation models are developed using ARENA software in such a way that the ammunition consumption of the artillery battalions, the movement of supply convoys, loading and unloading activities in ASPs, and the movement of artillery units during the battle time considering an eight-day battle of corps in an offensive operation. in its maximum and to test the reaction of the supply system are modelled in detail. The system is analyzed while the brigades are moving forward with the probability 1 for each day.

The entities of the models are the supply convoys. We use a control entity for reporting the consumed ammunition to the upper command level. The number of consumed ammunition and the number of vehicles in convoys are the attributes of the models. The performance measure are: time-in-system, waiting time in the queues, number of convoys waiting in the queues, utilization of the loading units, number of ammunition during the battle time, and minimum number of ammunition during the battle time.

In order to develop a valid model of the system, from the very beginning of this study, the actual users of the simulation system are included in the project to assure the model is behaving as expected in the real conditions. Since we have no opportunity to observe the real conditions, we included two of the personnel of the Army Logistics Department (ALD) as the users of the system and an instructor of the Military Operation Tactics course in Army.War Academy as a consultant for the military tactics of the model while we were constructing the conceptual model and showed the computer output results. At the end of this process they found the results reasonable and quite satisfactory (Banks, Carson, and Nelson, [2]). The data and the structural assumptions of the model were discussed with personnel of the ALD and the Army Ammunition Department. Within the bounds of our objectives they found these assumptions reasonable. We could not employ the statistical validation because of a lack of data from an actual war condition.

\section{EXPERIMENTAL DESIGN AND OUTPUT DATA ANALYSIS}

\subsection{Evaluation of the First Alternative System (System 1)}

Since the system is a terminating system, the simulation model stops when the ammunition level comes to zero. If the military units get the ammunition within one day's time while they're moving forward to the new positions, the units will have the opportunity to continue the battle. Unit Basic Load (UBL) that the units have at the beginning of the battle can satisfy the military units' ammunition needs for at most for two days. The results of the simulation experiments indicate that the existing system (System 1) doesn't work in some simulation runs (see Table 1).

Table 1. Summary Output Statistics for the First Alternative Ammunition Supply System (System 1)

\begin{tabular}{|c|c|c|c|}
\hline REP \# & $\begin{array}{c}\text { SIMULATION } \\
\text { RUN TIME }\end{array}$ & $\begin{array}{c}\text { UTILIZATION OF } \\
\text { LOADING UNIT }\end{array}$ & $\begin{array}{c}\text { AVG NO OF } \\
\text { CONVOYS } \\
\text { IN ASP QUEUE }\end{array}$ \\
\hline 1 & 11000 & 0.88 & 2 \\
\hline 2 & 5760 & 0.98 & 2 \\
\hline 3 & 11000 & 0.98 & 3 \\
\hline 4 & 11000 & 0.94 & 2 \\
\hline 5 & 11000 & 0.99 & 3 \\
\hline 6 & 10080 & 0.93 & 2 \\
\hline 7 & 7200 & 0.98 & 2 \\
\hline 8 & 1440 & 0.93 & 2 \\
\hline 9 & 8640 & 0.98 & 3 \\
\hline 10 & 5760 & 0.78 & 2 \\
\hline MEAN & 8288 & 0.94 & 2 \\
\hline VAR & 10401706.67 & 0 & 0.22 \\
\hline STD DEV & 3225.17 & 0.07 & 0.47 \\
\hline 95\% CI & 1998.94 & 0.04 & 0.29 \\
\hline MIN & 6289.06 & 0.90 & 2 \\
\hline MAX & 10286.94 & 0.98 & 3 \\
\hline
\end{tabular}

In general, with $95 \%$ confidence level, there are a minimum of 2 and a maximum of 3 convoys waiting in ASP loading queue. Besides the time consumption, the existence of convoys more than one makes it more susceptible for being a good target for the enemy air forces and the long distance weapons. It is unacceptable and risky to have a lot of vehicles waiting for loading due to the high possibility of being destroyed and losing the transportation capability at least within the scarce operation time limit. It is apparent that System 1 does not work for an eight-day battle time. Considering the other stochastic and dynamic events of the war conditions that are not included in the model, this system cannot satisfy the military needs. 


\subsection{Comparison of the Alternative Systems}

In this section, we will measure the performance of the proposed systems. We look at three main performance measures: "time in system", "time in ASP loading queue", and "time in the ASP". By comparing these three systems we try to understand their behavior of these systems and what makes them good or bad.

\subsubsection{Time in System Measure}

The capability of supplying the ammunition in time is an important factor from the point of being an effective supply system. The simulation results indicate that for the last position, which is $135 \mathrm{~km}$ far away the ASP, the third system supplies the unit with minimum 776 min (12.9 hours) and maximum $800 \mathrm{~min}$ (13.3 hours) with $95 \%$ confidence level. Considering the first system's reaction with even more than 1 or 2 day time, this is a significant improvement as the third system, which is a modified version of the first system, performs the job within half a day. What about the second and the fourth systems? The second system does it with minimum in 432 min (7.2 hours) and maximum 456 min ( 7.6 hours) with $95 \%$ confidence level; the fourth system accomplishes its mission with minimum in $353 \mathrm{~min}$ ( 5.9 hours) and maximum $356 \mathrm{~min}$ (6 hours) with $95 \%$ confidence level. Figure 1 presents the differences between the systems more clearly. Considering the results of the paired-t test, we say that there is a significant difference between the second and the third systems at 95\% confidence level. According to the results, the second system is better than the third system and the fourth system is better than the third system. Figure 2 shows these differences apparently. As depicted in Figure 1, differences between the third system and the other systems increase as the position number increases. That is why there exist a convoy movement between the battalion and ASP.

\subsubsection{Time in ASP Measure}

The results indicate that the second system is statistically better than the third system; but, considering the achievement of the mission according to the pre-determined standards by military, which seeks the system to supply within the night time, the third system achieve the same mission as well. As seen in Figure 1, the first system cannot accomplish its mission of supplying the military units for all positions during the battle time. Recall that in the third system there is a movement of convoys from the battlefield to the ASP as a difference between the second and the third system.

According to the results of paired-t test, "time passing in ASP" performances of the second and the third systems are statistically the same with $95 \%$ confidence level. This is apparent in Figure 2 which seems to be a crossover ef-

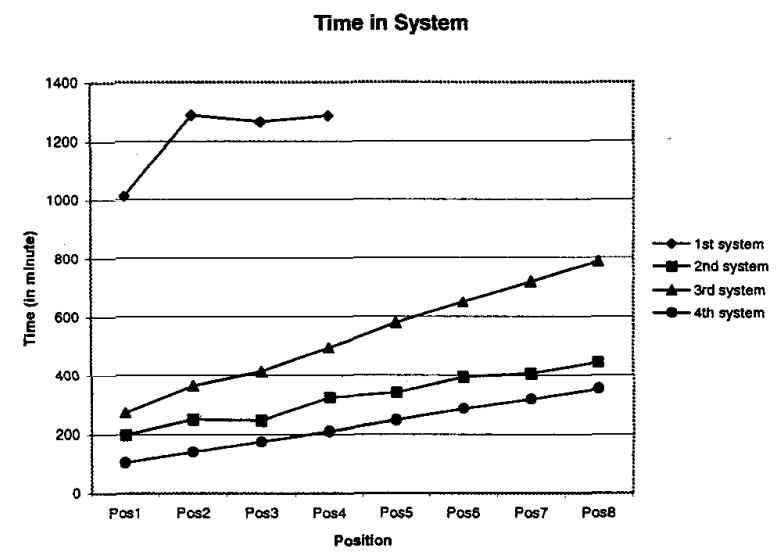

Figure 1. Performance of the Alternative Systems in Terms of "Time in System" Performance Measure

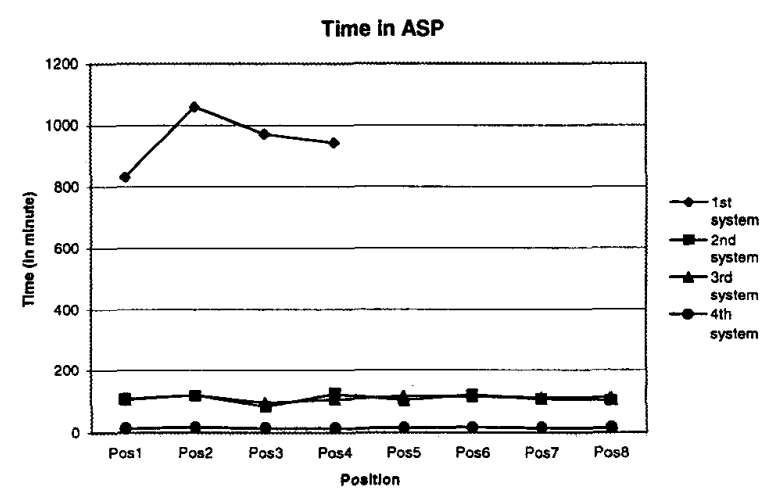

Figure 2. Performance of the Alternative Systems in Terms of "Time in ASP" Performance Measure

fect for second and third systems' performances. Fourth system is statistically better than second and the third systems with $95 \%$ confidence level. We conclude that the major problem with in the first system is the time passing in ASPs during the loading activities.

\subsubsection{Average Time in ASP Loading Queue Measure}

The waiting time of convoys in the ammunition loading queue makes them susceptible for the enemy target acquisition units and as the results of their reconnaissance for the attack of enemy long distance weapons, warplanes and units. The shorter time the units wait there the better from the point of the damage to be exposed. The worst of the systems (assuming that the first system does not work at all) is the second system which has minimum $90.44 \mathrm{~min}$ and maximum $96.88 \mathrm{~min}$ average waiting time in ASP loading queue with $95 \%$ confidence level. The third and the fourth systems have the same reaction with zero waiting time and both of them are better than the second one. 


\section{Sabuncuoglu and Utku}

\section{CONCLUDING REMARKS}

In this study, we developed a simulation model capable of analyzing the behavior of the different ammunition supply systems of army. We evaluate four alternative systems, compare each other by using three performance measures. The results indicate that the first alternative system does not accomplish its mission since it can not supply the ammunition during all phases of the battle. Among the proposed systems, the second alternative system is better except for the existence of convoy loading queue, which makes it susceptible to the enemy assaults. It costs more than the third system considering the changes to be made on the system, storage equipment and special vehicles containing material handling equipment. We also observe that convoy loading capacity is the most effective factor while keeping the loading time of a vehicle constant. But it is apparent that, considering the cost, the decision-maker may decide on a mixture of these two factors still having an effective result.

\section{REFERENCES}

D. C. Angelides. Material supply simulation for offshore pipelaying construction. Proceedings of the 1998 Winter Simulation Conference, 1297-1304, 1998.

J. J. Banks, J. S. Carson II and B. L. Nelson. Discrete Event System Simulation. Prentice-Hall, Inc., New Jersey, 1996.

M. Carr and H. Way. Million dollar logistic decisions using simulation. Proceedings of the 1997 Winter Simulation Conference, 1206-1209, 1997.

S. R. Parker. Ammunition upload and deployment V2.0: A simulation analysis. Proceedings of the 1990 Winter Simulation Conference, 878-883, 1990.

D. J. Parsons and L. C. Krause. Tactical Logistics And Distribution Systems (TLOADS) Simulation. Proceedings of the 1999 Winter Simulation Conference, 11741178, 1999.

\section{AUTHOR BIOGRAPHIES}

IHSAN SABUNCUOGLU is a Professor of Industrial Engineering at Bilkent University. He received the B.S. and MS. degrees in Industrial Engineering from Middle East Technical University and the Ph.D. degree in Industrial Engineering from the Wichita State University. Dr. Sabuncuoglu teaches and conducts research in the areas of simulation, scheduling, and manufacturing systems. He has published papers in IIE Transactions, Simulation, Decision Sciences, International Journal of Production Research, International Journal of Flexible Manufacturing Systems, International Journal of Computer Integrated Manufacturing, Computers and Operations Research, European Journal of Operational Research, Production Planning and Control, Journal of Operational Research Society, Computers and
Industrial Engineering. He is on the Editorial Board of International Journal of Operations and Quantitative Management. $\mathrm{He}$ is an associate member of Institute of Industrial Engineering and Institute for Operations Research and the Management Science. His email and web addresses are sabun@bilkent.edu.tr and <www.bilkent.edu.tr/ sabun>

HAKAN UTKU is a military officer in Turkish Army. Graduating with a Bachelor of Science degree in Management Science from the Turkish Military Academy. He received his MS degree in Industrial Engineering from Bilkent University, Turkey. His research interests include simulation and modelling of military systems. 